\title{
ORGANIZATIONAL SURVIVAL IN COOPERATION NETWORKS: THE CASE OF AUTOMOBILE MANUFACTURING
}

\author{
Pedro Campos \\ pcampos@fep.up.pt \\ Pavel Brazdil \\ pbrazdil@liacc.up.pt \\ Paula Brito \\ mpbrito@fep.up.pt \\ LIACC-NIAAD and \\ Faculty of Economics - University of Porto, PORTUGAL
}

\begin{abstract}
We propose a Multi-Agent framework to analyze the dynamics of organizational survival in cooperation networks. Firms can decide to cooperate horizontally (in the same market) or vertically with other firms that belong to the supply chain. Cooperation decisions are based on economic variables. We have defined a variant of the density dependence model to set up the dynamics of the survival in the simulation. To validate our model, we have used empirical outputs obtained in previous studies from the automobile. manufacturing sector. We have observed that firms and networks proliferate in the regions with lower marginal costs, but new networks keep appearing and disappearing in regions with higher marginal costs.
\end{abstract}

\section{INTRODUCTION}

According to economic evolutionary theories, firms innovate in order to increase their survival rates. We propose to analyze the dynamics of collective innovation, using a Multi-Agent framework, where firms (the agents) can cooperate for innovation purposes. To explore the impact of cooperation on the survival of organizations, we have used a variation of density dependence model (Campos and Brazdil, 2005b). We examined the empirical evidences from automobile manufacturing to improve our Multi-Agent model. Our main conclusion is that there are more networks in regions with lower marginal costs, but nevertheless there are some firms and networks in richer regions, showing that the firms clustering helps to avoid negative results and abandon of the activity. In the following we provide details concerning this study: in section 2 we provide an economic perspective of cooperation models and introduce some important concepts, as technological distance and density dependence. In section 3 , we present some concepts that are useful for the development of the model and in section 4 describe the Multi-Agent Simulation. Section 5 is devoted to the presentation of the results. We end this paper with conclusions and future work. 


\section{A NETWORK MODEL OF COOPERATION}

Because innovation is a strategic factor of the regional development, regional theory proposes that "new activity motivate power". Particularly and according to evolutionary theories, firms innovate in order to increase their survival rates. Some authors have related the process of innovation with the creation of networks of firms: Carayol and Roux (2003) consider innovation as a collective and interactive process that generates the formation of networks of organizations. Moreover, innovation and cooperation networks, and, generally, the topic of firms' dynamics have been recently studied with the help of Multi-Agent Simulation models (Zhang, (2003), Gilbert et al., (2001), Cowan et al, (2004), Cortés, (2004)).

One of the most important aspects related with cooperation networks and innovation is the distance between firms. Although the geographical distance is an important measure in literature from regional science, empirical evidence has shown that a non-physical distance between firms can also be useful. Some authors (Agata, 2003) call it cognitive or technological distance and it plays a major role in the effectiveness of knowledge diffusion that can be generated from inter-firm networks. This technological distance measures the distance between firm's knowhow and will be crucial for the definition of networks, as we will see.

\section{AUTOMOBILE INDUSTRY: SOME EMPIRICAL EVIDENCES}

To investigate how this model applies to reality, we have chosen to study the automobile manufacturing industry. In the following we present some concepts that are useful for the development of the model: (1) In automobile manufacturing, as car makers seek to cut costs, they outsource certain activities to the supply industry. (2) Outsourcing also allows greater economies due to specialization, since suppliers are more experienced in certain functions and can supply several carmakers, achieving higher efficiency or productivity. (3) Constructors promoted both the concentration process of component suppliers and room for creating important collaborations and alliances among suppliers and among suppliers and constructors (Rolo, 1998). (4) At the same time, we are facing the migration of OEM to emergent markets of Asia and South America as a way to rationalize production, and capacity reduction. In addition, previous studies of Campos and Brazdil (2005b) have confirmed the existence of factors affecting organizational survival, the number of organizations that existed at the time of birth and at the time of death (referred to as contemporaneous density and density at founding): (5) contemporaneous density has a negative impact on the mortality of organizations, while (6) density at founding has a positive impact on the mortality of organizations.

In the next section, we will introduce the model and discuss the components and the decision making process.

\section{MODEL DESCRIPTION}

A Multi-Agent model has been used, because agents can be configured to be autonomous, and these seem to capture the dynamics (and the survival) in network formation. 


\subsection{Model components}

The agents, knowledge creation and diffusion

We have developed a Multi Agent Model, NetOrg, where we have considered, for each market $\mathrm{y}, \mathrm{n}$ firms $\left(\mathrm{i}=1, \ldots, \mathrm{n}_{\mathrm{y}}\right)$ and $\mathrm{m}$ consumers $\left(\mathrm{j}=1, \ldots, \mathrm{m}_{\mathrm{y}}\right)$. There are three different markets defined by the products (or production process levels) $\mathrm{Y}=1,2$ and 3. Car makers, Carburetor suppliers and Clutches suppliers can be defined as examples of these types of markets or industries (as in Swaminathan, 2002).

For every product or production process level $(\mathrm{Y}=1,2,3)$, we consider a different kind of knowledge (or stock of capital) represented by $\mathrm{k}_{\mathrm{i}, \mathrm{Y}}^{\mathrm{t}}$ (the stock of capital or knowledge owned by firm $i$ in instant $t$ that is necessary to produce the product $Y$ ). In every step there will be an accumulation of knowledge $k$ given by:

$$
\begin{aligned}
& \mathrm{K}_{\mathrm{i}, \mathrm{Y}}{ }^{\mathrm{t}}=\mathrm{K}_{\mathrm{i}, \mathrm{Y}}{ }^{\mathrm{t}-1}+\Delta \mathrm{K}_{\mathrm{i}, \mathrm{Y}}{ }^{\mathrm{t}} \\
& \text { with, } A_{i, Y}{ }^{t}=\Delta K_{i, Y}{ }^{t}=w_{i, Y}{ }^{t}+\sum_{j \in N i j} \partial^{d^{t}(i, j)} w_{j, Y}^{t}
\end{aligned}
$$

where $\delta$ is the transferability factor, (i.e., the parameter that measures the share of new knowledge which is effectively transmitted through each link); $w_{i, Y}^{t}$ represents the innovation of firm $i$ that is related with product $Y$ at moment $t$ and it is defined by a Normal distribution; we have considered, (as in Carayol, 2003) that there is no knowledge diffusion (also known as knowledge spillover) between firms that do not share a network connection. Although each firm owns a value of the stock of capital for its particular level $y$, firms can also detain values for the stock of capital for other levels $(Y=1,2,3)$ because they can manufacture more than one product or interfere in more than one production process.

\section{Technology space / geographical space}

As stated before, we followed literature and have considered two types of distances that have been combined into one only weighted distance: (i) $\mathrm{d}^{\text {geo }}(i, j)$ represents the geographical distance measured by a Euclidean metric. We defined two different regions with different marginal costs associated: region 1 has higher marginal costs than region 2 ; (ii) $d_{Y}{ }^{\text {tec, }}(i, j)$ represents the technological (or cognitive) distance in instant $t$ for the product $Y$ and takes values in $[0,1]$. The final weighted distance was obtained by the formula: $d_{y}{ }^{t}(i, j)=\left[1-d_{y}{ }^{t e c}, t(i, j)\right] \cdot d_{y}{ }^{t e c}, t(i, j) \cdot\left[1-d^{g e o}(i, j)\right]$, which gives more importance to the technological distance. Considering, for instance, that two firms ( 1 and 2) have technological distance of 0.5 and if the geographical distance beween them is, say, 0.1 (geographical distances are normalized to 1), then

$$
\mathrm{d}_{\mathrm{y}}{ }^{\mathrm{t}}(1,2)=[1-0.5] \cdot 0.5 \cdot[1-0.1]=0.225
$$

\section{Cooperation and Market demand}

Some firms are assumed to produce in different markets or work in several levels of the production process (as in the example of carmakers, carburettors and clutches). Therefore, for two firms to cooperate in two or more levels of the production process they must first meet, through a preferential meeting process that will be described later. For the definition of the Market demand, we have considered three types of industries (as stated before), where, for each of the markets, consumers are assumed to have love-for-variety preferences (as in Wersching, 2005). Dealing with 
heterogeneity from demand side (different consumers), we can formulate the following utility function for each consumer in the market: $u_{j}^{t}\left(x_{1, j}^{t}, \ldots, x_{n, j}^{t}\right)=\left[\sum_{i=1}^{n} A_{i}^{t} \cdot x_{i, j}^{t}\right]^{1 / b_{1}}$ The constant $b_{j}$ is an indicator of the association of the products in the market: $b_{j}=1$, indicates that products are perfect substitutes. The quantities for the demand of product $i$ by consumer $j$ at time $t$ are represented by $X_{i, j}^{t}$. Consumer $j$ wants to maximize $u_{j,}^{t}$, under a budget constraint: $\max u_{j}^{t}\left(X_{1}^{t}, \ldots, X_{n}^{t}\right)$ such that: $\sum_{i=1}^{n} p_{j, i}^{t}, X_{i, j}^{t} \leq R_{j}^{t}$ where $R_{t}^{j}$ is the income of consumer $j$ in time $t$ and $p_{j, i}^{t}$ is the price that consumer $j$ pays for product $i$ at time $t$. The demand function (price) for the market of the good $\mathrm{i}$, is defined by:

$$
P_{i}^{t}=\frac{\left(A_{i}^{t}\right)^{b_{j}}}{\left(X_{i \infty}^{t}\right)^{1-b_{j}}} \cdot \frac{R_{\text {average }}^{t}}{\sum_{i=1}^{n}\left(A_{i}^{t}, X_{10}^{t}\right)^{b_{j}}}
$$

\section{Production costs}

The profit of a firm is obtained multiplying the quantity sold by the difference between unitary price and unitary cost. $g\left(\mathrm{w}_{\mathrm{i}}^{\mathrm{t}}\right)$ is the function of the effort needed to create knowledge. We have assumed that $g\left(w_{i}^{t}\right)=0.5\left(w_{i}^{t}\right)^{2}$ and that $c_{i}^{t}$ is the cost function of firm $i$ at time $t$ and will be modelled as: $c_{i}^{t}=c-\Delta k_{i}^{t}$, where $c$ is the marginal cost and $c_{i}^{t}$ is a function of the $i^{\text {th }}$ firms' cost at time $t$; $c_{i}^{t}$ integrates the effects of both innovation and absorption which are reduction production costs. From this, we can obtain a final form of the profit function for firm $i$ (considering a particular product $\mathrm{Y}): \pi_{\mathrm{i}}^{\mathrm{t}}=\left(\mathrm{P}_{\mathrm{i}}^{\mathrm{t}}-\mathrm{c}+\Delta \mathrm{k}_{\mathrm{Y}}{ }^{\mathrm{t}}\right) \cdot \mathrm{X}_{\mathrm{i}}^{\mathrm{t}}-0.5\left(\mathrm{w}_{\mathrm{i}}^{\mathrm{t}}\right)^{2}$

\subsection{Decision making}

\section{Entry/Exit and Production quantities}

The entry and exit in the market (birth and death processes) were defined by a variant of the density dependence model (Campos and Brazdil, 2005): if the number of organizations in the neighbourhood of a specific firm belongs to the survival interval $\left[D S_{1} ; D S_{u}\right]$, then the organization will have higher probability to stay alive. Otherwise it will have higher probability to die by the effect of "overcrowding" or "solitude", depending on whether the number is greater than $\mathrm{DS}_{\mathrm{u}}$ or lower than DS (where $\mathrm{DS}_{1}$ and $\mathrm{DS}_{\mathrm{u}}$ are respectively the lower and upper bounds of the density survival interval). The same idea applies to the process of founding where $\mathrm{DB}_{1}$ and $\mathrm{DB}_{\mathrm{u}}$ respectively are the lower and upper bounds of the density founding interval.

Every firm i must also decide about the quantities $X_{i}^{t}$, that will produce at instant $t$, having in mind the maximization of the profit. We have used a heuristic assuming that in the first step there is market equilibrium. In the following steps, we admit that when the profit of firm $i$ is positive the quantities will be increased by a factor $\alpha$ greater than 1 , otherwise, they will decrease: $\pi^{t-1}{ }_{i}>0 \Rightarrow \alpha>1 ; \pi^{t-1}{ }_{i} \leq 0 \Rightarrow \alpha<1$. 
As stated before, innovation at instant $t\left(\omega_{i}^{t}, y\right)$ depends on the accumulated knowledge by the firm. In each iteration, we consider that, if $\pi_{\mathrm{i}}^{\mathrm{t}}>0$, then the innovation $\omega_{i}^{t}$ must be not null. We have considered three Normal distributions for the innovations in each of the three markets. For the cooperation between two firms, we have defined the following steps: (i) preferential meeting process, where we have defined a meeting rate, $\mathrm{m}_{\mathrm{i}, \mathrm{j}}^{\mathrm{j}}$, between two firms where firm $\mathrm{i}$ chooses the firm $\mathrm{j}$ that maximizes the value $\mathrm{m}_{\mathrm{i}, \mathrm{j}}^{\mathrm{t}}=\left[1-\mathrm{d}^{\mathrm{t}}(\mathrm{i}, \mathrm{j})\right]$. (ii) Negotiation: a simple process was defined, in which two firms cooperate if they are able to reciprocally compensate some lack of profitability in the stock of capital (measured by $\pi_{\mathrm{i}}^{\mathrm{t}} / \mathrm{K}_{\mathrm{i}, \mathrm{Y}}^{\mathrm{t}}$ ) in some different phases of the production process. For example, if firm $i$ has higher profitability in the stock of capital than firm $j$, considering the product $Y=1$, but firm $j$ has higher profitability in the stock of capital than firm $i$ considering the product $Y=2$, than they can cooperate to invent a new kind of process that may increase the quantities they both produce. This process can be defined by the following condition: if $\left(\pi_{\mathrm{i}}^{\mathrm{t}} / \mathrm{K}_{\mathrm{i}, \mathrm{Y}=1}^{\mathrm{t}}\right)>\left(\pi_{\mathrm{j}}^{\mathrm{t}} / \mathrm{K}_{\mathrm{i}, \mathrm{Y}=1}^{\mathrm{t}}\right)$ and $\left(\pi_{\mathrm{i}}^{\mathrm{t}} / \mathrm{K}_{\mathrm{i}, \mathrm{Y}=2}^{\mathrm{t}}\right)<\left(\pi_{\mathrm{j}}^{\mathrm{t}} / \mathrm{K}_{\mathrm{i}, \mathrm{Y}=2}^{\mathrm{t}}\right)$ then $\Rightarrow$ cooperation (see example in table 1 ).

\section{RESULTS FROM NetOrg}

\subsection{Setting up initial parameters}

The results presented in this paper are the outcome of more than 100 different runs of the simulation (different runs of 10,15 and 20 generations were experienced). The following sections present one representative run of 15 generations from where we have taken one representative output. We have defined a set of initial parameters considering that industry 1 could represent an OEM manufacturer and industries 2 and 3 could be its suppliers. The price of the capital $\left(\mathrm{P}_{\mathrm{k}}\right)$ was set to the same value in all of the industries. The marginal cost was defined differently for the 3 types of industries, and marginal costs in region 2 were half of the corresponding values in the region 1 . We maintained the same parameters of the density dependence model in all the experiments $\left(\mathrm{DS}_{\mathrm{u}}=5 ; \mathrm{DS}_{\mathrm{l}}=1 ; \mathrm{DB}_{\mathrm{u}}=3 ; \mathrm{DB}=1\right)$. Knowing that $\mathrm{R}$ is the average income of the consumers of each market, the number of initial firms was defined by:

$$
\mathrm{n}=\frac{\mathrm{R}}{\mathrm{P}_{\mathrm{k}} \times \mathrm{K}_{\mathrm{i}, \mathrm{Y}}^{\mathrm{t}}} .
$$

\subsection{The emergence of networks}

A different $n$ was computed for the three different markets (in average $n_{1}=3, n_{2}=20$, and $n_{3}=20$ ). In all combinations of parameters, firms started cooperating with other firms in order to increase their profit. Firms (and networks) proliferate in region 2 (region with lower marginal costs). Some of the risky firms that migrate (from region 1 to region 2) were able to overcome negative profits. Some of them increased considerably their profits and became top success firms. Although it seems that firms with higher values of risk are in general more profitable, it appears that there is no direct association between the profit of the firm and its level of risk 
(Pearson correlation coefficient revealed a weak value of -0.067). Table 1 shows the negotiation results for the cooperation between the first 2 pairs of firms in the simulation, based on the indicator $\pi_{i}^{t} / K_{i, Y}^{t}$. Figure 1 shows the geographical space and the representation of the networks in the $15^{\mathrm{th}}$ generation.

Table 1: First two cooperations (over 98 in total) from one of the runs of NetOrg.

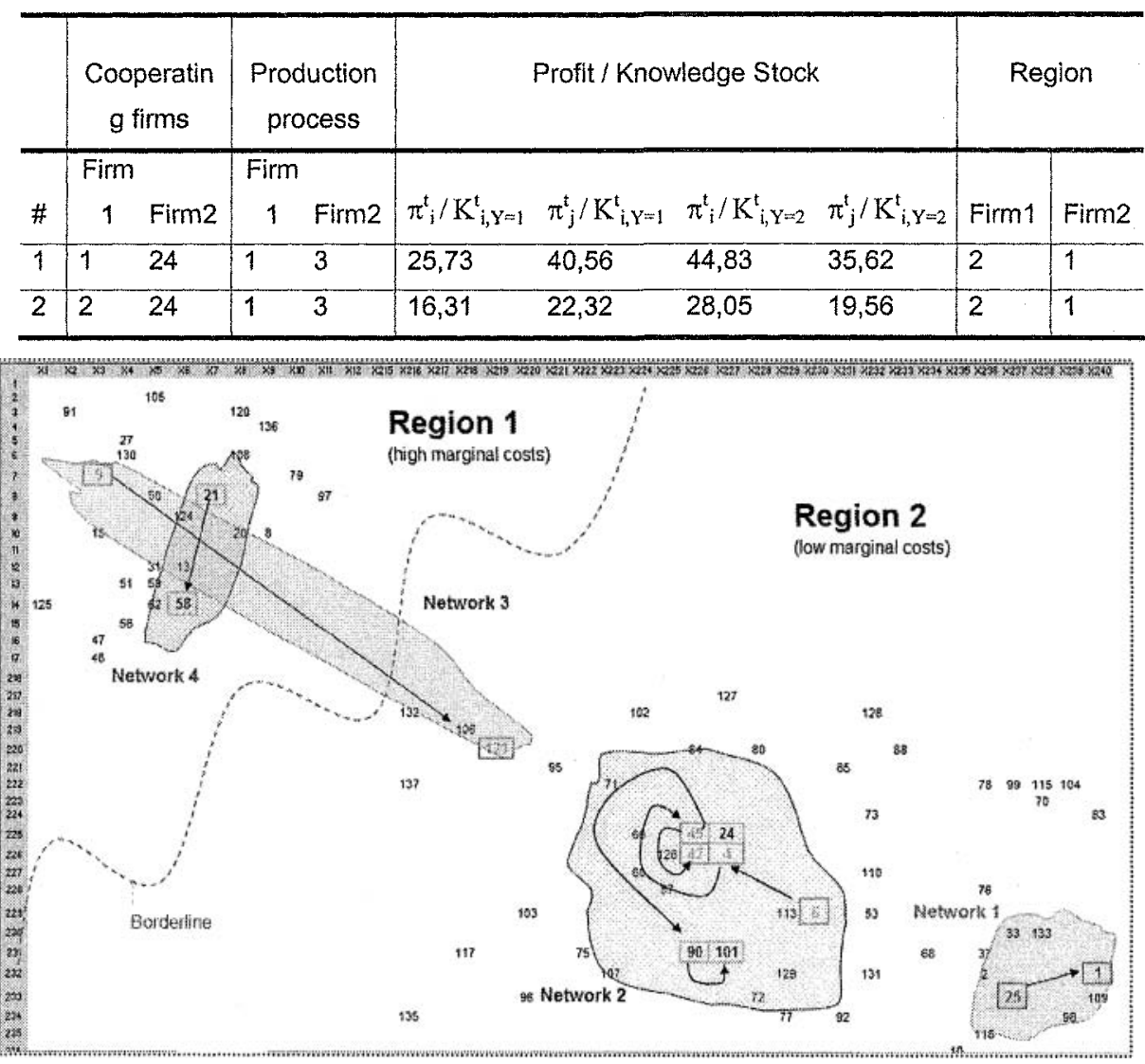

Figure 1 - Representation of the networks in the $15^{\text {th }}$ generation

\subsection{Validation of the Model}

To explore the strength of the model, we have considered, in section 3, some affirmations made in relation to the Automobile Industry: (3) Constructors promoted a concentration process of component suppliers (...); (4) OEMs migrate to emergent markets of Asia and South America as a way to rationalize production; (5) Contemporaneous density has a negative impact on the mortality of organizations; (6) Density at founding has a positive impact on the mortality of organizations Statistical measures can be used to evaluate the pertinence of these affirmations based on simulated data, but facts (1) and (2) are easy to confirm. In fact, in all iterations, NetOrg has produced tens of networks, most of them concentrated in one 
ore more OEM, (i.e., industries of type 1) and firms keep migrating to markets with lower marginal costs to increase their profits. To confirm the affirmations (3) and (4), we have analyzed the Regression coefficients from a Cox proportional Hazard Model, to estimate the impact of the covariates Contemporaneous density and Density at founding on the survival of organizations.

Table 2: Coefficients of some covariates obtained from Cox Regression.

\begin{tabular}{lcccc}
\hline \multicolumn{1}{c}{ Covariate } & $\begin{array}{c}\text { Predicted } \\
\text { Sign }\end{array}$ & Coef & se(coef) & p-value \\
\hline $\begin{array}{l}\text { Contemporaneous } \\
\text { Density }\end{array}$ & - & & & \\
\hline $\begin{array}{l}\text { Density at } \\
\text { Founding }\end{array}$ & + & -0.046 & 0.00992 & 0.0033 \\
\hline Size & - & -0.021 & 0.0013 & 0.0022 \\
\hline
\end{tabular}

We have compared the sign of the coefficients with those obtained in other works (Mata, Portugal and Guimarães, 1995; Carroll and Hannan 1989; Carroll and Hannan, 1992). The second column in Table 2 shows the predicted signs (obtained from literature; the same signs have been predicted in all studies) of the association between firm survival and the covariates. All the variables have a significant impact on the survival of firms, which can be seen from the p-values in last column (the standard error of the coefficients are represented as se(coef)). Carroll and Hannan (1989) explain that the density at founding has substantive implications on the survival of organizations. As we can see in Table 2, density at the time of a firm founding has a positive impact on the mortality of organizations while contemporaneous density (the number of firms existing at the moment of the death) has a corresponding negative effect. As expected, the effect of the size on firm survival is also negative, confirming what was said before and helping to validate the simulation model.

\subsection{Evolution of Networks}

We have also analyzed the evolution of networks to understand their behavior and change. Therefore, we have performed a Multiple Factorial Analysis (Dazy, 2001), which is suitable for evolutionary data, followed by a clustering step to group networks with similar behavior. Input data matrix contains some variables that describe the networks (profit, marginal cost, stock of capital and form of the network). Each observation in this matrix corresponds to a network in a total of 57 networks found in 20 runs of the simulation. Groups of variables have been considered (one for each period of time). In the global analysis of the Multiple Factorial Analysis (MFA), we kept 7 factors that represent more than $80 \%$ of the total model variance. In the cluster analysis, if we choose to accept a partition, say, in 2 classes, we must get a clear characterization of the clusters found. In this partition we find a first group composed by 32 individuals and another group of 25 . Looking to the networks (observations) that belong to each one of those classes, we may conclude that the clustering method has separated the networks with lower levels of the Stock of capital from those with higher values for the same variables. 
We observe that the networks are clustered considering the dimension of their stock of capital, a variable that is determinant for the growth of networks.

\section{CONCLUSIONS AND FUTURE WORK}

We have analysed the networks that have emerged from a process driven by agglomeration and collective innovation, using a Multi-Agent framework. We have concluded that there are more networks in regions with lower marginal costs. However, there are some firms and networks in richer regions, showing that the creation of networks helps to avoid negative results and abandon of the activity. This is related to the phenomenon of firm relocation that is apparent nowadays in the era of globalization. Although it seems that firms with higher values of risk are in general more profitable, it appears that there is no direct association between the profit of the firm and its level of risk. Clustering methods have found two different groups in the evolution of networks: networks with lower values of stock of capital and networks with higher values. There seems to be no association between the size of the networks and geographical location.

In the future, our goal is to continue endowing agents with the capacity of learning and trust and introducing strategies of cooperation. We will also analyze the stochastic stability of the model.

\section{REFERENCES}

1. Agata A, Santangelo GD. "Cognitive Distance, Kowledge Spillovers and Localisation in a Duopolistic Game 2003. mimeo, Catania

2. Campos, P., Brazdil, P. Density dependence and the survival of firms: a multi-agent approach, ABS'05: Workshop on Agent-Based Simulation, Erlangen, Germany, 2005b

3. Carayol N, Roux P. Self-Organizing Networks: when do small worlds emerge? $4^{\text {th }}$ EMEE

4. Carroll G, Hannan M. Density Delay in the Evolution of Organizational Populations: A model and Five Empirical Tests, Admnistrative Science Quaterly, 1989; 34: 411-430.

5. Carroll G, Hannan, M. The Demography of Corporations and Industries. Princeton University Press, Pinceton, New Jersey, 1992.

6. Dazy F, Le Barzic, J-F, L'Analyse des Données Evolutives, ed. Technip, Paris, 1996,

7. Cortés JCR, Sheremetov, LB. Model of Cooperation in Multi Agent Systems with Fuzzy Coalitions

8. Cowan R, Jonard N, Zimmernmann J-B. Networks as Emergent Structures from Bilateral Collaboration, MERIT, 2004-17

9. Gilbert N, Pyka, A, Ahrweiller. Innovation Networks - A Simulation Approach. Journal of Artificial Societies and Social Simulation 2001; 4,3

10. Mata, J. Portugal, P. and Guimarães, P., The Survival of New plants: start-up conditions and postentry evolution, in Intemational Joumal of Industrial Organization, $13,459-481,1995$

11. Rolo $T$. Contributo para análise dos factores de sucesso para a dinamizaçấo da cooperação interempresarial, Dissertation for Master of Sciences in Engineering Policy and Management of Technology, Instituto Superior Técnico - Universidade Técnica de Lisboa, Lisboa, 1998

12. Swaminathan A, Hoetker G, Mitchell W. Network Structure and Business Survival: The Case of U.S. Automobile Component Suppliers. Working Paper from the University of Illinois at Urbana Champagne, 2002

13. Wersching Klaus. Agglomeration in an Innovative and Differentiated Industry with Heterogeneous Knowledge Spillovers 2005; Workshop on Regional Agglomeration, Growth and Multilevel Governance: the E.U. in a comparative perspective, Ghent

14. Zhang, Jungfu. Growing Silicon Valley on a Landscape: an agent-based approach to high-tech industrial clusters. Journal of Evolutionary Economics 2003; 13: 529-548. 